Viso - Cadernos de estética aplicada

Revista eletrônica de estética

ISSN 1981-4062

NN 7, jul-dez/2009

http://www.revistaviso.com.br/
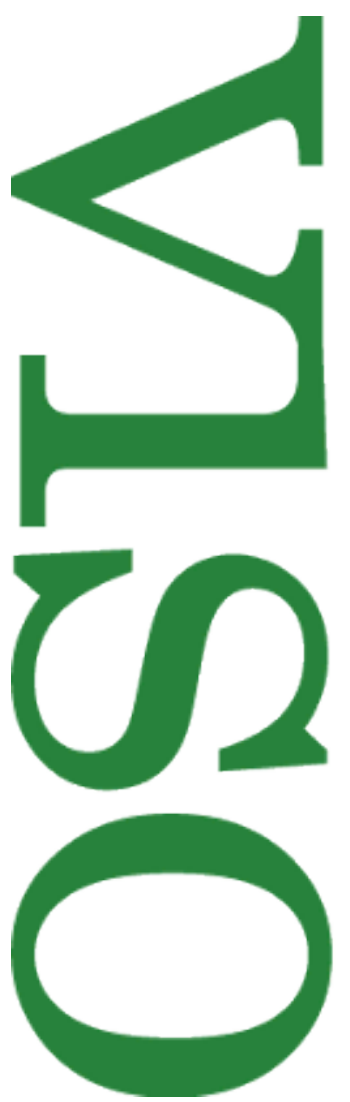

\title{
Hélio Oiticica. A criação e o comum.
}

\section{Tania Rivera}

Universidade de Brasília (UnB)

Brasília, Brasil 


\section{RESUMO}

Hélio Oiticica. A criação e o comum.

Este artigo corresponde a comunicação proferida na mesa "Criação" do Colóquio "Gênio, criação, autoria", organizado pela Revista Viso e pela Escola de Artes Visuais do Parque Lage, e realizado nas dependências dessa instituição entre os dias 03 e 05 de novembro de 2009.

Palavras-chave: Oiticica - arte contemporânea - arte brasileira - criação

\section{ABSTRACT}

Helio Oiticica. Creation and the ordinary.

This paper is a written version of the conference held at the "Creation" session of the Seminar "Genius, Creation, Authorship", organized by Revista Viso and Escola de Artes Visuais do Parque Lage. The Seminar took place in EAV between 11/03/2009 and $11 / 05 / 2009$.

Keywords: Oiticica - Contemporary art - Brazilian art -creation 
RIVERA, T. "Hélio Oiticica. A criação e o comum.". In: Viso: Cadernos de estética aplicada, v. III, n. 7 (jul-dezl 2009), pp. 13-26.

\section{DOI: $10.22409 / 1981-4062 / v 7 i / 76$}

Aprovado: 07.02.2010. Publicado: 23.02.2010.

(C) 2010 Tania Rivera. Esse documento é distribuído nos termos da licença Creative Commons Atribuição-NãoComercial 4.0 Internacional (CC-BY-NC), que permite, exceto para fins comerciais, copiar e redistribuir o material em qualquer formato ou meio, bem como remixá-lo, transformá-lo ou criar a partir dele, desde que seja dado o devido crédito e indicada a licença sob a qual ele foi originalmente publicado.

Licença: http://creativecommons.org/licenses/by-nc/4.0/deed.pt_BR

Accepted: 16.01.2010. Published: 23.02.2010.

(C) 2010 Tania Rivera. This document is distributed under the terms of a Creative Commons Attribution-NonCommercial 4.0 International license (CC-BY-NC) which allows, except for commercial purposes, to copy and redistribute the material in any medium or format and to remix, transform, and build upon the material, provided the original work is properly cited and states its license.

License: http://creativecommons.org/licenses/by-nc/4.0/ 
Bólide Lata, Apropriação 2, Consumitivo, realizado por Hélio Oiticica em 1966, consiste em uma lata contendo algum tipo de substância inflamável à qual é posto fogo. Hélio chama-o "lata-fogo" e diz tê-lo isolado "na anonimidade de sua origem". ${ }^{1}$ Essa invenção anônima e tão antiga é sem dúvida uma grande realização do homem, servindo como instrumento de iluminação e de sinalização, até hoje, em estradas, por exemplo. "Quem viu a lata-fogo isolada como uma obra", diz Hélio, "não poderá deixar de lembrar que é uma 'obra' ao ver, na calada da noite, as outras espalhadas como que sinais cósmicos, simbólicos, pela cidade". ${ }^{2}$

Se o artista se apropria desse objeto, nomeando-o como obra, não é para expô-lo no museu, à maneira de um ready-made de Duchamp. Para Oiticica, "museu é o mundo: é a experiência cotidiana". ${ }^{3}$ O que visa essa apropriação é reacender, em cada lata-fogo utilizada como sinalização nas obras da cidade, uma poesia que já estava lá, nessa criação anônima, perdida no tempo mas presente como prática coletiva. "Juro de mãos postas", escreve Hélio, "que nada existe de mais emocionante do que essas latas sós, iluminando a noite (o fogo que nunca apaga) - são uma ilustração da vida: o fogo dura e de repente se apaga um dia, mas enquanto dura é eterno". ${ }^{4}$

Quem a criou, essa lata-fogo? É ao isolá-la na anonimidade de sua criação (ao invés de, graças à assinatura do artista, retirá-la da anonimidade) que Hélio reacende sua poesia, acentuando o caráter de sinal ancestral que a conjuga à própria vida, ao tempo. Ao homem.

\section{A criação e sua excentricidade}

A etimologia do termo criação indica o significado de produzir, fazer crescer, impelir [creare], e também brotar, crescer [crescere], logo chegar à existência, nascer. O verbo creare teria sido inicialmente empregado na linguagem do campo. Posteriormente, na língua corrente, seria usado para todas as espécies de seres e objetos, com o sentido de fazer nascer. ${ }^{5}$

Foi a linguagem empregada pela Igreja que se valeu do verbo criar com o sentido religioso de fazer nascer do nada, atributo exclusivo de Deus, o Criador. ${ }^{6}$ No século XII, essa acepção está consolidada, carreada pela leitura do Gênesis (que em grego significa "origem", "nascimento", "criação") segundo a qual Deus cria o mundo e o homem do nada. O homem criaria. portanto, no uso consagrado do termo em francês no século XII, quando produz algo que não existia antes, à semelhança de Deus.

A origem anônima de nossa lata-fogo talvez possa ser conjugada a este uso original do termo na agricultura. Algo brota, não propriamente da terra, mas do solo da cultura, por assim dizer - neste solo comum aos homens. Negando o caráter de produção "a partir do nada", a lata-fogo se aproxima mais de outro sentido atribuído ao termo criar: aquele de nutrir uma criança ou um animal, instruir, educar. ${ }^{7}$ Há aí um processo latente, um 
certo cultivo, uma atividade humana materializada em um objeto, e que poderia se repetir e renovar a cada ocasião em que uma lata-fogo é vista na calada da noite. Esse olhar, essa memória da lata-fogo como obra humana, se repetiria em cada um de nós, graças à indicação do artista de tal objeto como uma criação.

Sabemos que apenas com o Renascimento o artista ganhará nomeação e reconhecimento. Apenas nas iluminuras do século XIV os artistas começam a assinar suas obras. Na pintura, Jan Van Eyck inaugura essa prática no século XV. Com a perspectiva, o artista começará a ocupar um ponto no espaço, ganhando um ponto de vista que se pode dizer individualizado. ${ }^{8}$ Ele inova um tanto, revê a técnica e a tradição a seu modo, e mecenas buscam seus serviços por sua singularidade. A fama dos mais talentosos atravessa fronteiras. Só nesse contexto começa a fazer sentido falar em criação artística. Se o artista se individualiza e emancipa do poder divino, deixando de ser um mero portador deste, é sob o modelo divino da criação ex-nihilo que seu mister parece ser reconhecido. $\mathrm{O}$ artista cria: ele traz ao mundo algo que, por mais que tenha a mímesis como eixo organizador, é um objeto sem igual no mundo. Talvez decorra disso a idealização de que ele é objeto, ao menos desde o famoso livro de Vassari As vidas dos mais excelentes pintores, escultores e arquitetos, publicado na metade do século XVI. ${ }^{9}$ Sob a valorização da invenção de que seria capaz o artista, pulsam em surdina, portanto, insuspeitados ecos do poder divino.

A criação no âmbito da arte, ao lado das científicas, na atuação dos grandes homens do Renascimento, talvez tenha reforçado a importância nascente do indivíduo singular ainda que este apareça inicialmente sob o modo de um humanismo que não exclui a comunidade, mas a reforça e transmite na figura do indivíduo. Grosso modo, pode-se dizer que durante toda a época moderna o ideal da criação como atributo do artista se mantém quase intacto, acentuando-se contudo em direção a um individualismo mais marcado. As vanguardas de fins do século XIX e da primeira metade do século XX talvez pudessem tê-lo atacado mais impiedosamente, de posse de dispositivos como a escrita automática e o objet trouvé dos surrealistas e, principalmente, contando com o golpe certeiro desferido pelo ready-made duchampiano. Neste, de fato, a criação é radicalmente criticada, consistindo em nada além de um gesto, uma certa torção como aquela sofrida pela roda de bicicleta ao ser colocada de ponta-cabeça sobre um banquinho de cozinha em 1913 (Roda de Bicicleta). O artista não é mais um criador a partir do nada - ele não faz nascer um objeto propriamente novo, mas rearranja os objetos corriqueiros do mundo e os nomeia como arte.

Tal nomeação simbólica traz insuspeitados ecos do curioso emprego que toma o termo criar no século XIV: aquele que denota instituir, nomear (alguém) para uma função, como a de papa ou cônsul. Na linguagem jurídica, creare começa a ter o sentido especial de alcançar a magistratura ou eleger. Nomear é instituir alguém em uma certa posição simbólica: de um homem cria-se um juiz, ou um cardeal. De uma coisa qualquer se pode, de modo análogo, criar um objeto de arte. 
Com esta nomeação, esta apropriação que institui simbolicamente um objeto no campo da arte, chegamos perto do que Walter Benjamin concebe como o artista moderno: o trapeiro, o catador de lixo que recolhe os dejetos, a escória da sociedade e os reapresenta, renomeados e portanto instituídos no seio de um campo simbólico especial, o da arte. Poderia este artista-catador ser ainda caracterizado como um "criador"?

Ele não tem mais a pretensão de, à maneira de Deus, criar a partir do nada. Ele recolhe o que a sociedade despeja e despreza. A partir do lixo encontrado nas ruas, o artista faria, segundo Benjamin, sua "crítica heróica". ${ }^{10}$ A criação revira-se em crítica. Deixando de se ocupar em trazer à luz objetos valorizados pela sociedade, a arte assumiria a tarefa de pôr o mundo em crise e, nele, estenderia para o homem o dedo que aponta a crise em seu seio. Se o artista moderno faz uma crítica heróica, esse herói moderno está ele mesmo em crise, ele não é mais do que um "representante do herói", segundo o filósofo. ${ }^{11}$ Representante um tanto precário, seu lugar não parece bem estabelecido. Ele talvez seja cambiante, deixando de ocupar o ponto de vista fixo e individualizado que a perspectiva artificialis Ihe asseguraria (ou ao menos Ihe teria facultado). Baudelaire muda de fisionomia várias vezes por dia, segundo a queixa de Courbet ao fazer seu retrato. Introduz-se aí uma certa quebra, uma fratura, na ausência de um ponto de vista fixo e central. "A modernidade heróica", diz Benjamin, "revela-se como tragédia em que o papel do herói está disponível". ${ }^{12}$

Neste contexto, a criação deixa de refletir o lugar central de Deus para ser vista, ainda nos termos de Benjamin inspirados por Freud, como choque, trauma. Essencialmente, segundo nos parece, porque ela descentraria o sujeito, o faria retomar e comemorar sua condição ex-cêntrica; ou seja, a impossibilidade de ocupar um centro organizador e préestabelecido que reconfigura o sujeito - não mais como um "indivíduo", mais ou menos separado, porém intimamente co-dependente da "sociedade", mas antes como um sujeito dividido em seu seio e deslocado, assimétrico em relação a qualquer princípio organizador do mundo. Este sujeito de que a psicanálise é a clínica e a principal teoria.

\section{O objeto e a inscrição do sujeito no espaço}

É do nada que Jacques Lacan faz vir a sublimação, ao caracterizá-la em 1960 como criação ex-nihilo. Em vez de retomar por essa via a potência criadora do homem ecoando a posição divina, o psicanalista acentua o lugar da criação como falta. A arte elevaria um objeto qualquer "à dignidade da Coisa". ${ }^{13}$ Um ato criador buscaria preencher a vacância instalada pela perda do objeto primordial que faz de cada um de nós um sujeito desejante. Mas este objeto jamais poderá ser recuperado, e tudo que for colocado em seu lugar poderá apenas substituí-lo parcialmente. Qualquer objeto pode, portanto, ser potencialmente usado para conformar este nada. Caixas de fósforo, por exemplo, na ornamentação que Lacan aprecia na casa de Jacques Prévert durante a Segunda Guerra. É o objeto desvalorizado, o único que sobra na penúria de uma guerra, o insignificante, o resto, o indigno que é "criado". Tal criação refere-se muito menos à 
particularidade ou "originalidade" do objeto do que, diríamos, a uma operação que incide sobre o laço entre sujeito e objeto. A instituição deste último no campo simbólico da arte implica uma sutil retomada da estrutura do desejo, pondo em primeiro plano o sujeito. Para tal, basta um "toque", nas palavras de Hélio:

A obra nasce de apenas um toque na matéria. Quero que a matéria de que é feita a minha obra permaneça tal como é; o que a transforma em expressão é nada mais que um sopro: sopro interior, de plenitude cósmica. Fora disso não há obra. Basta um toque, mais nada. ${ }^{14}$

Um toque, e mais nada - esse objeto torna-se outra coisa, apesar de continuar o mesmo. Como diz Mário Pedrosa sobre os bólides: "Como que deixando o macrocosmo, tudo agora se passa no interior desses objetos, tocados de uma vivência estranha". ${ }^{15}$ Estranhamente vívido, tornado familiar, o objeto dá notícias de nós mesmos.

Vai nesse sentido a bela frase que o mesmo Mário Pedrosa escrevia em 1951: "A obra de arte vive subjetivamente". ${ }^{16}$

O vazio conformado pela criação tem como modelo o vaso, que Lacan toma de Heidegger. O oleiro produz com sua mão um vaso, ao fazer nascer na matéria da argila um furo, um côncavo, uma cavidade. O vaso, esse objeto singular, utensílio simples, talvez seja "o elemento mais primordial da indústria humana", lembra Lacan ${ }^{17}$ : ele inaugura a possibilidade do vazio e do cheio. Esse vazio é um espaço, diz o psicanalista - e nós acrescentaríamos: um espaço para o sujeito. "O exercício na parede consiste em fixar o habitante invisível da cavidade", diz Lacan. ${ }^{18}$

Sobre "a área aberta ao mito", cercado circular vedado por treliça, na instalação Éden (1969), diz Hélio que

a área vazia interior é o campo para a construção total de um espaço significativo "seu": não há "proposição" aqui - estar-se nu diante do fora-dentro, do vazio, é estar-se no estado de "fundar" o que não existe ainda, de se autofundar. ${ }^{19}$

Não se trata aí necessariamente da instauração de um ponto de vista, de um lugar fixo e pré-determinado para o indivíduo, mas de um espaço aberto ao surgimento do sujeito. A criação não é mais produção do objeto a partir de um agente inquestionado, mas referese a uma produção do próprio sujeito graças à incitação de uma certa conformação espacial.

O vaso de argila pode ser visto, nesse sentido, como uma espécie de modelo da origem da arquitetura, nas cavernas (esses vasos horizontais, de certa maneira) onde os homens pré-históricos vinham inscrever suas pinturas rupestres. Por que eles o faziam nas galerias escuras, em vez de expô-las à luz do dia? Eles aí carregavam tochas que não deixam de ser as ancestrais das latas-fogo - e que modelavam o olhar como 
limitado, dando-Ihe algum enquadramento, ainda que um tanto móvel, ao sabor do bruxuleio das chamas (chegando talvez a criar a ilusão de movimento).

Esse enigma ancestral nos toca através dos séculos, ensinando sobre a criação da imagem como indissociavelmente ligada à origem da arquitetura - espaçamento necessário para que se inscreva um sujeito no ato criador da própria cultura. O espaço é arquitetônico justamente ao se conformar como lugar para o sujeito - os limites concretos de uma edificação, assim como de uma caverna, a delimitam em relação ao ambiente circundante criando uma área interna que se opõe a um exterior, mas a conformam, ao mesmo tempo, como externa ao sujeito. A caverna dá o modelo deste interno/externo, esse fora/dentro de que fala Hélio, desse êxtimo, no neologismo de Lacan: instauração simbólica de uma exterioridade íntima, lugar onde o mais íntimo (o sujeito) só se instaura no exterior (na cultura).

Essa fixação do "habitante invisível da cavidade", essa autofundação de que fala Hélio, se dá, curiosamente, sobre algo que já estava lá. Diferenças de cor ou textura na superfície das paredes são por vezes incorporadas às pinturas rupestres - o gesto sobre o elemento da natureza institui a Cultura como significantização desta. Além disso, em muitas delas imagens são sobrepostas a inscrições anteriores, criando uma espécie de palimpsesto. Como se, em vez de individualizar seu "criador", ao fixá-lo na cavidade e dar-Ihe um lugar, cada traço buscasse enlaçá-lo a um habitante anterior. Quem seria o autor de tal escrita plural onde se inscreve o sujeito?

Nessas pinturas rupestres se manifesta que "existe um encontro secreto, marcado entre as gerações precedentes e a nossa", como diz Benjamin, completando: "Alguém na Terra está à nossa espera". ${ }^{20}$ Cada objeto, cada obra de arte talvez esteja na terra à nossa espera, dando notícias de um alguém que é cada um de nós.

Vem daí o que Lacan aponta como "possibilidade original de uma função como a função poética em um consenso social no estado de estrutura". ${ }^{21}$ Apesar de ecoar o senso comum de Kant, tal consenso social não estaria ligado à homogeneidade de julgamento, à universalidade de um juízo estético normativo. Ele parece, antes, indicar a existência de um certo compartilhamento social na origem da própria inscrição do sujeito. O campo da arte exerceria tal função, ou melhor, exploraria tal base comum de modo a comemorar o surgimento do sujeito na cultura.

Para Lacan, a invenção da perspectiva virá conformar o vazio, construindo um espaço na pintura, de modo a conceder nela um lugar, uma posição para o homem. Isso sob um modo ilusionista que não deixa, porém, de quebrar um tanto a ilusão, ir além dela para reafirmar-se como representação. A rapidez com que a própria construção perspectiva renascentista dá lugar a uma proliferação do uso da anamorfose, já no século XVI, mostra que ela revira-se em crítica, ou seja, põe em crise seus meios constitutivos. ${ }^{22} \mathrm{~A}$ mímesis estaria sempre submetida a essa tensão entre a semelhança ilusória e a construção significante, entre a proximidade e um certo distanciamento em relação ao 
referente. E é na própria distância - aquela que a perspectiva constrói ativa e artificialmente - que algum lugar é concedido ao indivíduo. À medida que se acentua, a partir da passagem para o século XX, a constatação de que, nas palavras de Freud, "o eu não é mais senhor em sua própria casa" ${ }^{23}$, tal lugar é questionado e o espaço passa a ser convocado como campo aberto a um surgimento imprevisível do sujeito. Não mais indivisível, mas dividido em suas bases, o sujeito não é senhor da representação, mas torna-se a meta a ser atingida por um complexo arranjo significante que, eventualmente, materializa o espaço no real. Em um instante efêmero, o sujeito pode então surgir, problemático e incerto. Mas capaz de se autofundar num ato poético que não deixa de ter uma dimensão política.

\section{O parangolé e sua ética}

Segundo Oiticica em texto de 1966, haveria no campo da produção artística "uma tal liberdade de meios, que o próprio ato de não criar já conta como uma manifestação criadora". ${ }^{24}$ Desse não criar surge então uma "necessidade ética de outra ordem de manifestação": a "manifestação social, incluindo aí fundamentalmente uma posição ética (assim como uma política)". ${ }^{25}$ Essa posição não é partidária, ideológica, ela talvez seja anárquica porque baseada numa liberdade radical, mas ela é política num sentido mais amplo e fundamental, o de uma verdadeira ética.

É nessa medida que "a antiarte é a verdadeira ligação definitiva entre manifestação criativa e coletividade". ${ }^{26} \mathrm{~A}$ coletividade é a dimensão da extimidade necessária para o surgimento do sujeito, da poesia. O objeto é a isca capaz de capturar essa poesia anônima e coletiva: "Acham-se 'coisas' que se vêem todos os dias mas que jamais pensávamos procurar. É a procura de si mesmo na coisa - uma espécie de comunhão com o ambiente". ${ }^{27} \mathrm{O}$ sujeito busca a si mesmo na coisa, e a coisa, como a lata-fogo, é já uma manifestação do poder criador humano, anônimo, coletivo. Ao surgir na coisa, o sujeito é fora de si: é anônimo, é um comum (apesar de radicalmente singular).

A respeito desta reviravolta, o termo definitivo, conceitualmente preciso em Oiticica, é aquele de parangolé. Ele é de saída coletivo, e "antiarte por excelência". ${ }^{28}$ Este termo indicaria algo não totalmente formulável, algo que resiste à formulação intelectual, uma certa provocação. Trata-se de um termo literalmente achado "na rua", como conta Hélio a Jorge Guinle Filho poucos dias antes de sua morte:

Isso eu descobri na rua, essa palavra mágica. Porque eu trabalhava no Museu Nacional da Quinta, com meu pai, fazendo bibliografia. Um dia eu estava indo de ônibus e na praça da Bandeira havia um mendigo que fez assim uma espécie de coisa mais linda do mundo: uma espécie de construção. No dia seguinte já havia desaparecido. Eram quatro postes, estacas de madeira de uns 2 metros de altura, que ele fez como se fossem vértices de retângulo no chão. Era um terreno baldio, com um matinho e tinha essa clareira que o cara estacou e botou as paredes feitas de fio de barbante de cima a baixo. Bem feitíssimo. E havia um pedaço de aniagem pregado num desses barbantes, 
que dizia: "aqui é..." e a única coisa que eu entendi, que estava escrito era a palavra parangolé. Aí eu disse: "É essa a palavra". ${ }^{29}$

Em seu texto para o "Esquema geral da nova objetividade", Hélio diz que gostaria que se manifestassem, nessa exposição, as "experiências coletivas anônimas" que "determinaram inclusive minha formulação do parangolé"..$^{30}$ Parangolé já era mais ou menos definida, na gíria, como "agitação súbita, animação, alegria e situações inesperadas entre pessoas". ${ }^{31}$ Algo se passa entre as pessoas, um acontecimento imprevisível. Quem o cria? Ele vem das "experiências coletivas anônimas", e o artista não faz mais do que tentar reavivá-las, essas experiências vívidas, essa anonimidade que dá notícias de cada um de nós.

Também sobre a instalação Éden, Oiticica afirma, como en passant: "Nunca me senti tão contente quanto com este plano do Éden. Senti-me completamente livre de tudo, até de mim mesmo" ${ }^{32}$ É na medida dessa despersonalização do artista no contexto de uma sofisticada concepção crítica do que é obra e criação que se impõe a participação do espectador:

Anti arte-compreensão ( $\mathrm{sic}$ ) e razão de ser do artista, não mais como um criador para a contemplação, mas como um motivador para a criação - a criação, como tal, se completa pela participação dinâmica do 'espectador', agora considerado 'participador'. Anti-arte seria uma completação da necessidade coletiva de uma atividade criadora latente, que seria motivada de um determinado modo pelo artista: ficam portanto invalidadas as posições metafísicas, intelectualistas e esteticistas - não há proposição de um 'elevar o espectador a um nível de criação', a uma 'meta-realidade', ou de imporIhe uma 'ideia' ou um 'padrão estético' correspondente àqueles conceitos de arte, mas de dar-Ihe uma simples oportunidade de participação para que ele 'ache' aí algo que queira realizar - é pois uma 'realização criativa' o que propõe o artista [...], é uma simples posição do homem nele mesmo e nas suas possibilidades criativas vitais. $\mathrm{O}$ 'não achar' também é uma participacão importante [...]. ${ }^{33}$

Trata-se, com a "participação", de apelar para uma potência coletiva de "criação" que é (re)criação poética do sujeito, no objeto, no outro, na cultura em suas raízes, de forma subversiva e transformadora. Mais do que produzir algo, trata-se apenas de um achar, de um encontro, de um parangolé, que não é tanto o achar algo, mas um achar-se: mesmo não achar é participar porque a "posição do homem nele mesmo" é uma posição do homem fora dele, na caverna onde outros já inscreveram algo.

Assim, a nomeação da lata-fogo como obra de arte por Hélio não só faz daquela lata ready-made - um objeto artístico, como faz do encontro com qualquer lata-fogo uma experiência poética (ou seja, uma verdadeira experiência). Bastou um gesto, um toque sobre uma lata com querosene em fogo para encher nossas noites na estrada (e nossos dias, em casa ou em qualquer lugar, pouco importa) de encontros com esses sinais deixados por um outro (desconhecido, anônimo). Essa chama me é endereçada, de um modo que me faz anônimo porém singular. Ela me toca como uma inscrição rupestre: para mim, fazendo-se no momento de meu olhar, apesar de datar de milhares de anos. Com que poesia o sujeito se assujeita ao tempo, ao olhar, ao outro! 
Encontro de si, na coisa. O objeto encontrado dá notícias do sujeito - de seu fogo. Criação é encontro. Como dizia André Breton na idéia básica ao objet trouvé, "nada do que nos cerca nos é objeto, tudo nos é sujeito". ${ }^{34} \mathrm{~A}$ ambigüidade do termo sujet, que designa na língua francesa tanto "sujeito" quanto "tema", mostra bem o território híbrido de que se trata, a torção, o encontro que faz, do tema, o próprio sujeito.

Sobre os "Subterranean Tropicália Projects", originalmente em inglês, Hélio grafa:

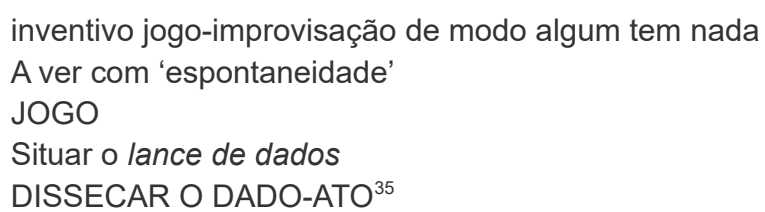

No poema de Mallarmé a que alude Oiticica, marco do que viria a ser a literatura e a arte do século XX, "cai a pluma". ${ }^{36}$ Ela, que já era "solitária e perdida", não resiste ao naufrágio do homem (homem "sem nau"). Seu gesto torna-se não mais que o "fantasma de um gesto", submetido a algo maior, ao acaso que brinca com o sujeito deste gesto, assujeitando-o. O ato é "vazio", pois o acaso de um lance de dados é quem faz o poema - e o sujeito. E, no encontro entre os dois, a poesia. "Um lance de dados jamais, jamais abolirá o acaso" - a aposta que ele representa não faz dele ato de alguém, mas reafirma o acaso. Trata-se, com esse lance, esse golpe, da suposição de um outro maior, porém não absoluto, onisciente ou intencional como Deus. Ele não tem o poder de criar do nada, mas apenas de brincar com os dados - que já estão justamente, se me permitem o jogo de palavras, dados. Ele talvez seja como o "Número": exato representante da ordem simbólica à qual estamos todos submetidos.

Barthes, no seu "A morte do autor", diz ter sido Mallarmé o primeiro a substituir o escritor, aquele que supostamente seria proprietário da linguagem, pela linguagem nela mesma. "É a linguagem que fala", diz Barthes, "não o autor". ${ }^{37}$ Suprimindo o autor em favor da escrita (ou escritura), é ao leitor que Mallarmé dará um lugar de destaque. Na medida em que há linguagem, nela estamos todos - não por acaso fala-se em "língua materna": talvez a língua nos crie.

Em texto sobre as Cosmococas, Hélio escreve:

o lance de dados de Mallarmé colocou em cheque a obra: não é obra nem não-obra.

É uma coisa nova.

É UMA COISA NOVA! $!^{38}$

A "coisa nova" de que fala Oiticica não é ex-nihilo, do nada, produto do gênio criador à imagem e semelhança do Criador. Ela é "nada ou quase uma arte", como diz Mallarmé do futuro de seu poema. ${ }^{39}$ Ela é uma aposta, um lance de dados pelo qual o artista 
convoca o "coletivo", a cultura, a manifestar mais uma vez o parangolé no qual nasce o sujeito, poeticamente.

"Nada terá tido lugar senão o lugar", na afirmação do poema. Mas do inelutável naufrágio do homem singular e independente, estrela nascida na modernidade, resta "uma constelação", ao fim do poema. É dela o "pensamento": "Todo pensamento emite um lance de dados". (E talvez daí decorra o que diz Bataille: "o que eu penso, não o pensei sozinho" $\left.{ }^{\prime 4}\right)$.

Assim descentrado, o artista não-herói, ou anti-herói, marginal (marginetical, como diz Hélio) não é propriamente quem cria, quem faz, mas se deixa "criar".

Não ocupar um lugar específico, no espaço ou no tempo, assim como viver o prazer ou não saber a hora da preguiça, é e pode ser a atividade a que se entregue um "criador". ${ }^{41}$

A condição de criador aparece aí entre aspas, criticada, ironizada. A noção de "crelazer" dá mostras da mesma ironia, fazendo Hélio chegar a afirmar: "Crer no lazer, que bobagem, não creio em nada, apenas vivo". Um pouco abaixo, o artista debocha: "Prefiro a salada da vida, o esfregar dos corpos. Quero meu amor!"42

Essa posição não deixa de ecoar a séria fórmula de Ovídio: Amor regendus arte. Com o amor, Hélio parece anunciar o que um Jean-Luc Nancy dirá na defesa de um 'comum' para além do comunismo, após a queda do muro: "não existimos sós. Ou antes, não há só que exista". ${ }^{43}$

Em uma carta a Guy Brett em 1968, Oiticica afirma:

\begin{abstract}
Sinto que a idéia cresce para a necessidade de uma nova comunidade, baseada em afinidades criativas, apesar da diferença cultural ou intelectual, ou mesmo sociais e individuais. $^{44}$
\end{abstract}

Tais "afinidades criativas" são uma verdadeira comparição, para usar o conceito cunhado por Nancy: "nós comparecemos: nós viemos juntos ao mundo". ${ }^{45}$ Como na caverna onde deixamos um traço no palimpsesto aí já inscrito, em movimento sob as tochas que os fazem visíveis, aparecemos junto - apesar de em oposição ao outro. O comum aí não conota um pertencimento a uma substância única, totalmente homogênea, mas a partilha de uma falta de essência - e a necessidade de inventar (a si mesmo e ao mundo) que dela decorre. Nas palavras ainda de Hélio:

O novo seria a emergência de um estado de invenção no qual eu cheguei, que ele se torne um mundo, um edifício sólido e coletivo. Essas coisas são um prelúdio ao estado de invenção coletivo. ${ }^{46}$

Desta invenção coletiva o parangolé é um programa ou um processo, uma "estrutura não opressiva" que revela uma "potencialidade viva de uma cultura em formação: [...] a possibilidade aberta de uma cultura". ${ }^{47}$ A própria raiz ("raiz-aberta", na expressão do 
artista), as origens da cultura brasileira não estariam simplesmente dadas historicamente, mas restariam a realizar - tarefa para a qual a vanguarda artística viria dar uma importante contribuição.

A cultura é tomada aí como um processo, que iria não só em direção ao futuro, mas também ao passado, retroativamente, numa constante reinvenção. Ao mesmo tempo estética e ética, a cultura é um parangolé que só se faz com nosso corpo, com nosso olhar, com alguma ginga, eventualmente. Criação comum e, no entanto, íntima.

\section{* Tania Rivera é professora adjunta da UnB.}

${ }^{1}$ OITICICA, H. "Programa Ambiental". In: Catálogo da Exposição Hélio Oiticica. Rio de Janeiro, 1996, p. 104.

2 Ibidem.

${ }^{3}$ Ibidem, p. 103.

${ }^{4}$ Ibidem, p. 104.

${ }^{5}$ ERNOUT, A.; MEILLET, A. Dictionnaire étymologique de la langue latine: histoire des mots. Paris: Klincksieck, 1979. Agradeço a Laura Parisi por sua cuidadosa pesquisa etimológica.

${ }^{6}$ Ibidem. Todas as demais observações etimológicas têm nesta obra sua principal fonte.

${ }^{7}$ Conforme indica COROMINAS, J. Diccionario crítico etimológico de la lengua castellana. Madrid: Gredos, 1954.

8 Como nota Tzvetan Todorov em seu "La Représentation de l'individu en peinture". In: FOCCROULLE, B.; LEGROS, R.; TODOROV, T. La Naissance de l'individu dans l'art. Paris: Grasset, 2005.

${ }^{9}$ VASSARI, G. The Lives of the Most Excellent Painters, Sculptors and Architects. Nova York: Modern Library, 2006.

${ }^{10}$ BENJAMIN, W. A modernidade e os modernos. Rio de Janeiro: Tempo Brasileiro, 2000, p. 15.

${ }^{11}$ Ibidem, p. 28.

${ }^{12}$ Ibidem.

${ }^{13}$ LACAN, J. Le Séminaire. Livre VII. La Sublimation. Paris: Seuil, 1986, p. 133. Eu traduzo esta e todas as demais citações em língua estrangeira.

${ }^{14}$ Texto de 6 de setembro de 1960. In: Catálogo da Exposição Hélio Oiticica. Rio de Janeiro, 1996, p. 32.

${ }^{15}$ PEDROSA, M. "Arte ambiental, arte pós-moderna, Hélio Oiticica". In: Dos murais de Portinari aos espaços de Brasília. São Paulo: Perspectiva, 1981, p. 208.

${ }^{16}$ PEDROSA, M. "Forma e personalidade". In: ARANTES, O. (org.) Forma e percepção estética. São Paulo: Edusp, 1996, p. 220.

${ }^{17}$ LACAN, J. Op. cit., p. 144.

${ }^{18}$ Ibidem, p. 168.

${ }^{19}$ OITICICA, H. Aspiro ao grande labirinto. Rio de Janeiro: Rocco, 1986, p. 136. 
${ }^{20}$ BENJAMIN, W. "Sobre o conceito da história". In: Obras escolhidas. Magia e técnica, arte e política. São Paulo: Brasiliense, 1994, p. 223.

${ }^{21}$ LACAN, J. Op. cit., p. 174.

${ }^{22}$ Ver BALTRUSAITIS, J. Les Perspectives dépravées. Tome 2: Anamorphoses. Flammarion: Paris, 1996.

${ }^{23}$ FREUD, S. "Vorlesungen zur Einführung in die Psychoanalyse" (Conferências Introdutórias sobre Psicanálise) (1917). In: Gesammelte Werke, Londres: Imago, 1944, vol. XI, p. 295.

${ }^{24}$ OITICICA, O. "Programa ambiental". In: Catálogo da Exposição Hélio Oiticica, op. cit., p. 103. Itálicos nossos.

${ }^{25}$ Ibidem.

${ }^{26}$ Ibidem, pp. 104-105.

${ }^{27}$ Ibidem, pp. 105.

${ }^{28}$ Ibidem, pp. 103.

${ }^{29}$ FIGUEIREDO, L. (org.) Hélio Oiticica. A pintura depois do quadro. Rio de Janeiro: Silvia Roesler, 2008, pp. 264-265.

${ }^{30}$ OITICICA, O. "Esquema geral da nova objetividade". In: Catálogo da Exposição Hélio Oiticica, op. cit., p. 114.

31 OITICICA, O. "Bases fundamentais para uma definição do Parangolé". In: Catálogo da Exposição Hélio Oiticica, op. cit., p. 88.

32 OITICICA, H. "Éden”. In: Catálogo da Exposição Hélio Oiticica, op. cit., p. 12.

${ }^{33}$ OITICICA, H. "Posição e Programa, julho de 1966". In: Catálogo da Exposição Hélio Oiticica, op. cit., p. 100.

34 "Rien de ce qui nous entoure ne nous est objet, tout nous est sujet". BRETON, A. Le Surréalisme et la peinture. Paris: Gallimard, 1965, p. 56 (Folio/Essais).

35 "inventive play-improvisation has nothing whatsoever / to do with 'spontaneity'/ GAME / situate the coup de dès / DISSECT THE DICE-ACT”. OITICICA, O. Catálogo da Exposição Hélio Oiticica, op. cit., p. 150.

${ }^{36}$ MALLARMÉ, S. "Um lance de dados jamais abolirá o acaso". Tradução de Haroldo de Campos. In: CAMPOS, A.; PIGNATARI, D.; CAMPOS, H. Mallarmé. São Paulo, Perspectiva, 2006, pp. 153173.

${ }^{37}$ BARTHES, R. "La Mort de l'auteur". In: Le Bruissement de la langue. Paris: Seuil, p. 64 (Points/Essais).

${ }^{38}$ OITICICA, O. Catálogo da Exposição Hélio Oiticica, op. cit., p. 184.

${ }^{39}$ MALLARMÉ, S. Op. cit, p. 52.

${ }^{40}$ Apud BLANCHOT, M. La Communauté inavouable. Paris: Les Éditions de Minuit, 1983, p. 16.

${ }^{41}$ OITICICA, H. "Crelazer". In: Catálogo da Exposição Hélio Oiticica, op. cit., p. 132.

42 Ibidem, p. 133.

43 NANCY, J.-L. "La Comparution”. In: NANCY, J.-L.; BAILLY, J.-Ch. La Comparution. Paris: Christian Bourgois, 2007, p. 56.

${ }^{44}$ OITICICA, H. Catálogo da Exposição Hélio Oiticica, op. cit., p. 135.

${ }^{45}$ NANCY, J.-L. “La Comparution”, op. cit. p. 57. 
${ }^{46}$ Declaração de Oiticica a Ivan Cardoso. Apud DAVID, C. "O Grande labirinto". In: Catálogo da Exposição Hélio Oiticica, op. cit., p. 258.

${ }^{47}$ OITICICA, H. "As possibilidades do crelazer". In: Catálogo da Exposição Hélio Oiticica, op. cit., p. 137. 